\title{
Auflösung
}

\section{Burkittlymphom der Nebenhöhlen (hochmalignes B-Zell-Lymphom)}

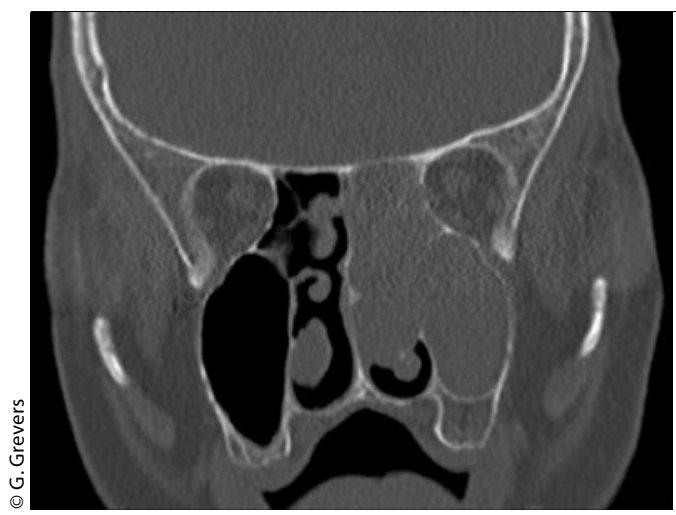

höhle (Abb.). Die Endoskopie hatte keinerlei Hinweis auf ein Malignom ergeben; im Gegenteil, makroskopisch zeigte sich das klassische Erscheinungsbild der Polyposis nasi. Auffällig war in diesem Zusammenhang dennoch das Alter des Patienten in Verbindung mit der rasanten Entwicklung der Beschwerdesymptomatik, insbesondere der einseitig behinderten Nasenatmung. Entsprechend führten wir den Eingriff zeitnah durch. Intraoperativ imponierte das Gewebe deutlich konsistenter als von „normalen“ Nasenpolypen gewohnt, und erinnerte eher an ein invertiertes Papillom. Die histologische Auswertung ergab dann ein hochmalignes B-Zell-Lymphom/ Burkittlymphom der Nasennebenhöhlen.

\section{Therapie}

Der Tumor wurde soweit makroskopisch möglich, operativ entfernt. Da die Staging-Untersuchungen (CT Thorax und Abdomen) keinen Hinweis auf weitere Lymphommanifestationen ergaben, wurde postoperativ die isolierte Radiatio der Nasennebenhöhlen links eingeleitet. Anderenfalls wäre eine Chemotherapie indiziert gewesen.

Prof. Dr. med. Gerhard Grevers

Nasen-Zentrum Starnberg

Prinzenweg 1

82319 Starnberg

\section{Blickdiagnosen auf springermedizin.de}

